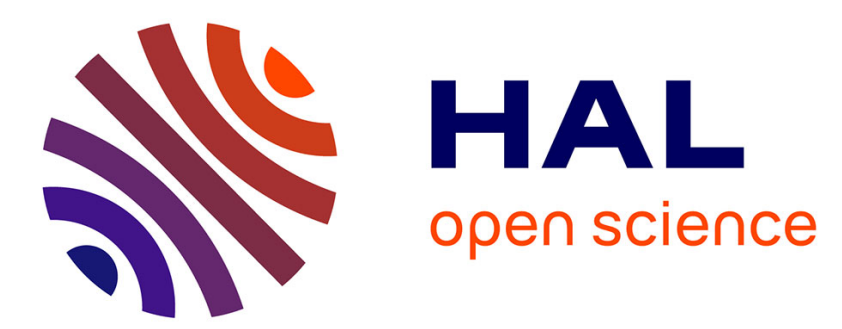

\title{
Improvement in quality of life after botulinum toxin injection for temporomandibular disorder
}

\author{
S. Villa, G. Raoul, F. Machuron, J. Ferri, R. Nicot
}

\section{To cite this version:}

S. Villa, G. Raoul, F. Machuron, J. Ferri, R. Nicot. Improvement in quality of life after botulinum toxin injection for temporomandibular disorder. Journal of Stomatology, Oral and Maxillofacial Surgery, 2019, 120, pp.2 - 6. 10.1016/j.jormas.2018.10.007 . hal-03486601

\section{HAL Id: hal-03486601 \\ https://hal.science/hal-03486601}

Submitted on 20 Dec 2021

HAL is a multi-disciplinary open access archive for the deposit and dissemination of scientific research documents, whether they are published or not. The documents may come from teaching and research institutions in France or abroad, or from public or private research centers.
L'archive ouverte pluridisciplinaire HAL, est destinée au dépôt et à la diffusion de documents scientifiques de niveau recherche, publiés ou non, émanant des établissements d'enseignement et de recherche français ou étrangers, des laboratoires publics ou privés.

\section{다)(1) $(5$}

Distributed under a Creative Commons Attribution - NonCommerciall 4.0 International 
Version of Record: https://www.sciencedirect.com/science/article/pii/S2468785518302180

Manuscript_bdd9182889271cf6096c33490d9b9c3a

\section{IMPROVEMENT IN QUALITY OF LIFE AFTER BOTULINUM TOXIN INJECTION FOR TEMPOROMANDIBULAR DISORDER}

Sidonie Villa ${ }^{1}$, Gwénael Raoul ${ }^{1}$, François Machuron ${ }^{2}$, Joël Ferri ${ }^{1}$, Romain Nicot ${ }^{1}$

1. Univ Lille, Department of Oral and Maxillofacial Surgery, CHU Lille, Lille, France;

2. Univ. Lille, CHU Lille, EA 2694 - Santé Publique : Épidémiologie et Qualité des

Soins, Department of Biostatistics, F-59000 Lille, France

Address correspondence and reprint requests to Dr Villa: Departement de Chirurgie MaxilloFaciale et Stomatologie, Hop R. Salengro - CHU Lille, 2 avenue Oscar

Lambret, 59037 Lille Cedex; E-mail: sidonie.villa@gmail.com

Keywords: Quality of life, Botulinum toxin type A, Temporomandibular disorder 


\section{IMPROVEMENT IN QUALITY OF LIFE AFTER BOTULINUM TOXIN INJECTION FOR TEMPOROMANDIBULAR DISORDER}

\section{ABSTRACT:}

Background: Temporomandibular disorders (TMDs) cause chronic pain and interfere with quality of life (QoL). Botulinum toxin is one of the treatment modalities popularly used for TMDs. The primary objective of this retrospective study was to evaluate improvement in QoL after botulinum toxin injections in patients with TMD.

Methods: Twenty-eight patients diagnosed with TMD were included in this study. In accordance with the Research Diagnostic Criteria for Temporomandibular Disorders, all patients had myofascial pain. They received botulinum toxin A (BTX-A) injections in temporalis and masseter muscles. QoL was measured using a French translated version of the validated Oral Health Impact Profile-14 (OHIP-14) and a second questionnaire, which was an adaptation of the temporomandibular joint replacement QoL questionnaire (TMJ-QoL). Patients answered both questionnaires and a visual analogue scale (VAS) before the injection, at 1 month after the injection and at 3 months after the injection. Relationship between QoL and factors such as bruxism, age, sex and body mass index (BMI) were also evaluated.

Results: All patients reported significant improvements in QoL (OHIP-14 and TMJQoL) and VAS scores at 1 and 3 months after BTX-A injections $(p<0.0001)$. A 
significant moderate positive correlation was noted between TMJ-QoL before BTX-A injections and $\mathrm{BMI}(\mathrm{p}=0.016)$.

Conclusion: Overall, QoL in patients with TMD improved significantly at 1 and 3 months after BTX-A injections. BTX-A injection in masticatory muscles of patients with TMD can be a useful supportive therapy to control pain and improve QoL.

\section{INTRODUCTION}

Temporomandibular disorders (TMDs) have been known since the 20th century and have been extensively researched. In fact, multiple factors contribute toward its aetiology [1]. TMDs are influenced by several mechanical, structural, systemic and psychosocial determinants which generate chronic disorders and have marked and profound effects on daily life. Varying degrees and types of pain of the temporomandibular joint can originate either from the joint himself or can be secondar to hyperfunctioning of masticatory muscles [2].

Several lines of treatment have already been suggested for TMDs: pharmacological treatment, physiotherapy, behavioural approach, psychotherapy, occlusal splints, or surgical treatment [3]. At present, there is no consensus regarding the most effective treatment approach. Botulinum toxin is one of the treatment modalities proposed in literature. The painful and chronic characteristics of TMDs interfere with the quality of life (QoL) of patients [4]. Botulinum toxin has a double action on the neuromuscular junction: first, inhibition of acetylcholine release leads to degeneration of nerve endings and consequently paralysis; second, botulinum toxin decreases inflammatory pain by inhibiting substance $\mathrm{P}$ and glutamate release [5]. 
The first study, dating back to 1998 [6][7], demonstrated that botulinum toxin reduces pain and improves mobility in patients with dysfunction of the masticatory system [8][9]. However, no study has investigated QoL after injection of botulinum toxin in patients with TDMs; the present retrospective study aimed to evaluate the same.

\section{MATERIALS AND METHODS}

\section{Patients}

This retrospective study was conducted at the Lille University Hospital. Given the current lack of consensus regarding the therapeutic management of TMDs, the QoL questionnaires and EVA were systematically collected at our institution on a prospective basis since November 2016. Patients with TMDs treated with botulinum toxin A (BTX-A) injections from November 2016 to September 2017 were analysed. TMD was assessed using routine clinical examination performed by the same maxillofacial surgeon before injection treatment and entered into the Research Diagnostic Criteria for Temporomandibular Disorders (RDC/TMD) [10]. In accordance with RDC/TMD, all patients had at least myofascial pain. Body mass index (BMI) and presence of bruxism were also evaluated in each patient.

\section{BTX-A injection technique}

Type-A botulinum toxin was Botox reconstituted with $1 \mathrm{~mL}$ physiological saline for $100 \mathrm{U}$ of Botox. Patients received a total of $150 \mathrm{U}$ of BTX-A injections into bilateral 
masseter and temporalis muscles [11][12]: $50 \mathrm{U}$ per masseter muscle was divided into three injection sites and $25 \mathrm{U}$ per temporalis muscle was divided into two injection sites (Fig. 1).

QoL evaluation

Various approaches can be used to measure oral health-related QoL. We selected two QoL questionnaires.

The first was an adaptation of the Oral Health Impact Profile questionnaire (OHIP-14) (Table 1). OHIP-14 is a questionnaire designed to measure self-reported discomfort, functional limitation and disability due to oral conditions. It is derived from an original version of 49 items developed by the World Health Organization and adapted for oral health by Locker [13]. The scores range from 10 to 50.

The second questionnaire was an adaptation of the temporomandibular joint replacement quality of life questionnaire (TMJ-QoL) (Table 2). It consists of 12 questions, which cover physical, functional and psychosocial aspects of patients' lives [14]. The scores range from 12 to 60.

Treatment efficacy was evaluated by measuring pain on a visual analogue scale (VAS), with scores ranging from 0 to 10.

All patients answered both questionnaires and VAS before BTX-A injection, at 1 month after injection and at 3 months after injection. Any reduction in scores represented improvement in QoL. No missing data was reported for any of the recruited patients. All patients provided written informed consent for data collection and presentation. 
Statistical analysis

Quantitative variables were described using mean and standard deviation. Normality of distributions was verified with the help of graphs and the Shapiro-Wilk test. On the other hand, qualitative variables were described using frequencies and percentages.

Evolution of patients' QoL (TMJ-QoL and OHIP-14) and pain (VAS) from baseline (injection) to 1 and 3 months after injection was appreciated using longitudinal mixed models.

Correlation between age, BMI and QoL was calculated using Pearson's correlation coefficients. Moreover, correlation between sex, bruxism and QoL was assessed using student's t-tests. In case of non-normality of data, nonparametric Wilcoxon tests were used.

The threshold for significance was set at 0.05. Analyses were performed using SAS software version 9.4 (SAS Institute, Cary NC, USA).

\section{RESULTS}

In total, 28 patients with TMD (17 women, 11 men) were included. The mean patient age was $45.0 \pm 14.0$ (range: $18-68$ ) years, and the average BMl was $25.4 \pm 6.2$. All patients presented myalgia of masticatory muscles. Associated to TMD, the most commonly diagnosed condition was disc displacement (32\%), followed by TMDrelated headache (10.5\%) and arthralgia (7\%). Disc displacement without reduction 
was the least common Axis I diagnosed condition (3.5\%). Bruxism was noted in 21 patients. None of the patients reported any adverse effects after injection.

QoL assessment

Significant improvement in QoL (TMJ-QoL and OHIP) was noted at $1(p<0.0001)$ and 3 months after BTX-A injection $(p<0.001)$ (Fig. 2).

Pain assessment

All patients reported significant improvements in VAS scores $(p<0.001)$ at 1 and 3 months after BTX-A injection (Fig. 2).

Association between QoL and other factors: bruxism, age, sex and BMI

No significant association was identified between improvement in QoL after BTX-A injection and age, sex and bruxism. However, a significant positive but moderate correlation (Pearson Correlation Coefficient of 0.45 ) was noted between TMJ-QoL before BTX-A injection and BMI $(p=0.016)$, indicating the relative importance of $B M I$. As the correlation is positive, hight BMI would be associated with hight TMJ-QoL scores before BTX-A injection, which, in turn, would indicate a worse QoL (Table 3).

\section{DISCUSSION}


Management of TMD, a multi-factorial and polysymptomatic pathology, cannot be univocal and must be customized on case-by-case basis. Permanent muscle involvement in various mechanisms of the temporomandibular joint and consequently TMD justifies the use of multiple muscle-relaxant therapies such as botulinum toxin. Although botulinum toxin has not been proven superior over other treatments for TMD, it is a part of the therapeutic arsenal with a good risk-to-benefit ratio. Treatment for TMD aims to relieve algebraic attacks and break the vicious cycle of chronic pain. Findings from our study, like various other publications, confirmed improved pain relief after botulinum toxin injections [15]. A previous study proved a correlation between severity of TMD and its impact on QoL [16]. In the present study, improvement in QoL was significantly greater at 1 month after injection compared with at 3 months after injection; this finding was consistent with reports from previous studies, wherein the maximum effect of treatment was obtained after 1-4 weeks, which lasted for up to 3-6 months depending on individual patients [17].

The World Health Organization defined Health (1947) as 'a state of complete physical, mental and social well-being, and not only as the absence of disease'. This definition incorporates both social and psychological aspects. Thus, level of health must be assessed within the larger framework of QoL.

In general, health-related QoL takes into account not all dimensions of QoL but only those which can be modified by the disease, including the physical condition of the patient, somatic sensations (symptoms, therapeutics, pain, sequelae), psychological state (emotionality, anxiety, depression) and social relations (relation to the family environment, friendly or professional). 
OHIP is recognised as being specific to oral functions [18]. As no French version is available, we created a translated version (as accurate and faithful as possible) of the same. This questionnaire included 10 questions grouped into seven domains: functional limitation, physical pain, psychological discomfort, physical incapacity, psychological incapacity, social incapacity and handicap.

However, as a disadvantage, the OHIP scoring system lacks clarity regarding certain issues. Nuances between discomfort and disability are sometimes difficult to grasp, and inaccurate interpretation could affect the scores obtained. Nevertheless, OHIP was chosen as an assessment tool because of its international recognition and its use in several recent studies [19]. The second QoL questionnaire TMJ-QoL was chosen because of its greater specificity regarding symptoms, which affect the temporomandibular joint, but this questionnaire has not yet been validated. In our study, improvement in pain levels had, independent of associated psychopathological comorbidities, a reverberating impact on daily life by improving somatic sensations, psychological state as well as social relations, and consequently QoL on the whole.

In a previous study, TMD was more prevalent in women than in men, but no gender differences were noted in terms of its impact on QoL [16]. However, in the present study, no correlation was identified between age, gender, as well as bruxism and improvement in QoL after BTX-A injections, which could probably be explained by the insufficient statistical power of the study. On the other hand, a positive correlation was observed between high BMI and lower QoL in patients with TMD. Several studies have investigated the relationship between TDM and obesity with discordant results. In a recent study, Rhim et al. found that TMD was associated with low BMI 
and abdominal obesity in women [20], whereas no such correlation has been found in other studies [21][22].

Our study had certain limitations. It is a monocentric study with a small sample size. In addition, subjective interpretation of questionnaires could have altered the results. Furthermore, several other factors, which could have affected QoL, were perhaps not taken into account, such as patients taking treatments other than BTX-A injections and presence of multiple pathologies other than TMDs.

\section{CONCLUSION}

Clinical injection of BTX-A in masticatory muscles of patients with TMD can be considered as a useful supportive treatment option to control pain and improve QoL. However, additional studies with larger samples are required to extrapolate these results, perhaps a randomised, double-blind, placebo-controlled trial testing a null hypothesis.

\section{DISCLOSURE OF INTEREST}

The authors declare that they have no competing interests. 


\section{FIGURES}

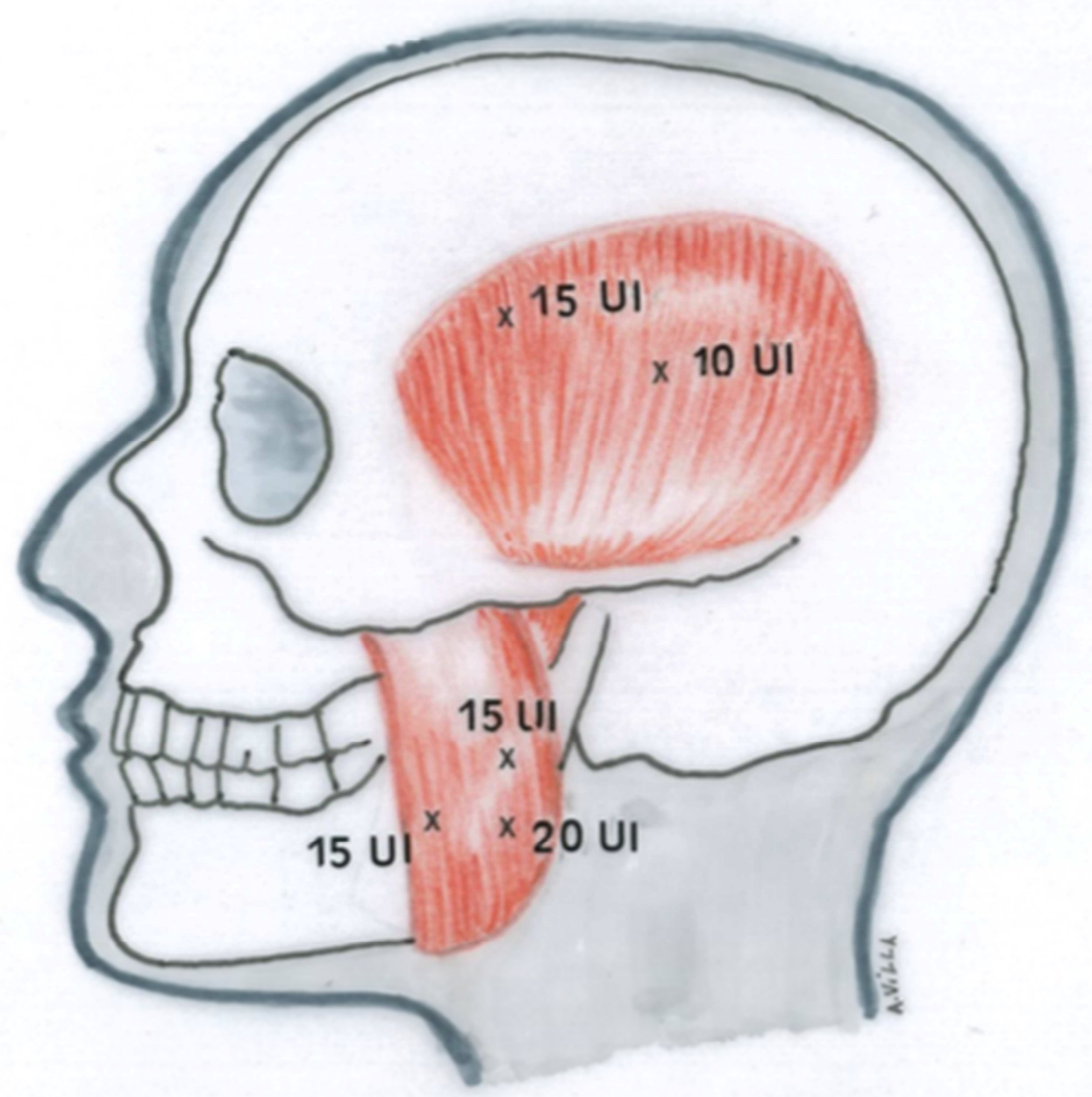

Fig. 1. BTX-A injection distribution in temporal and masseter muscles 
Evolution of TMJ-QOL

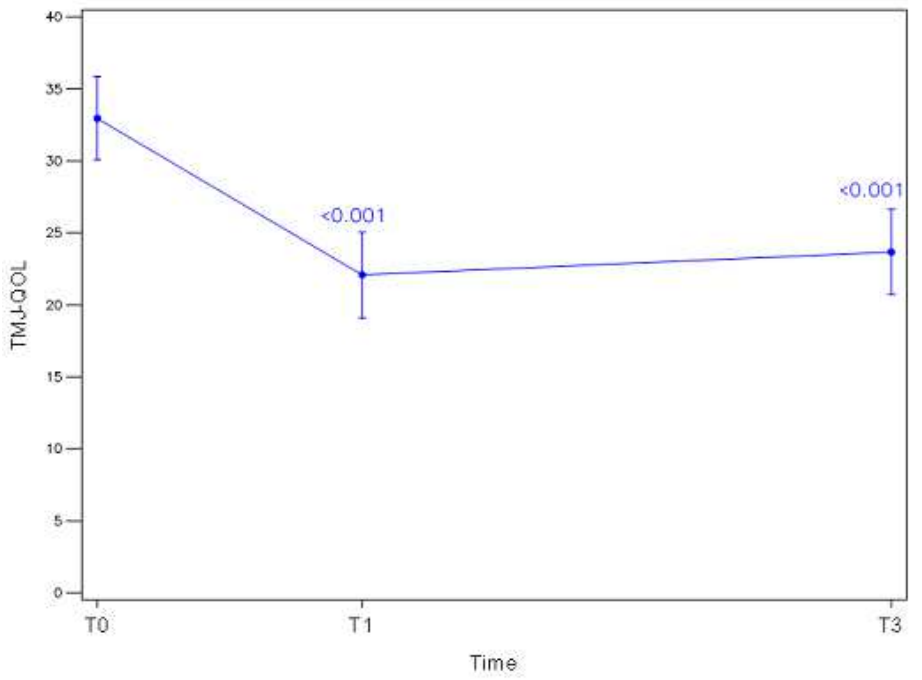

Evolution of OHIP-14

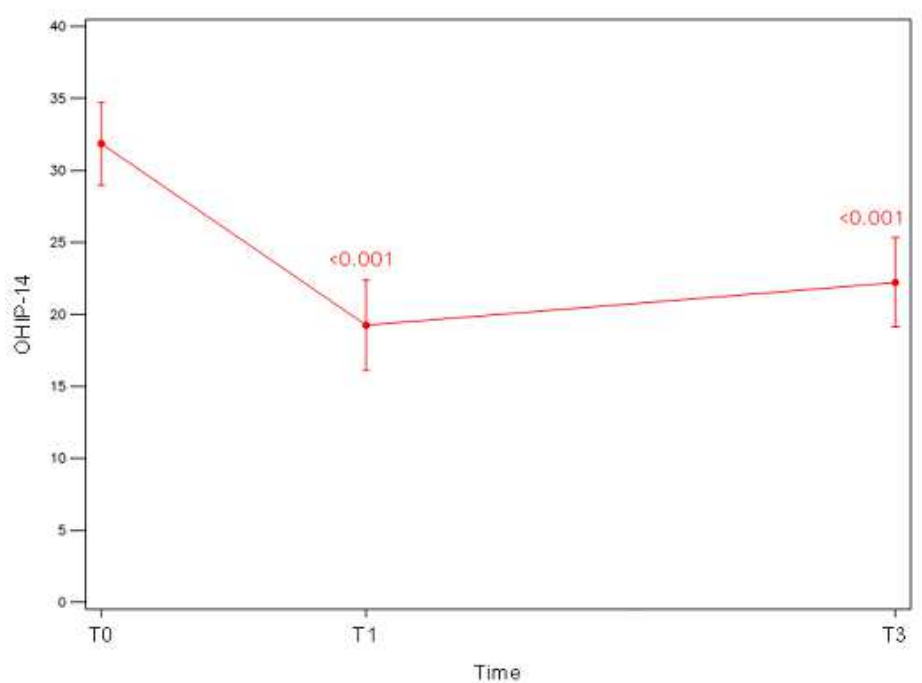

Evolution of VAS

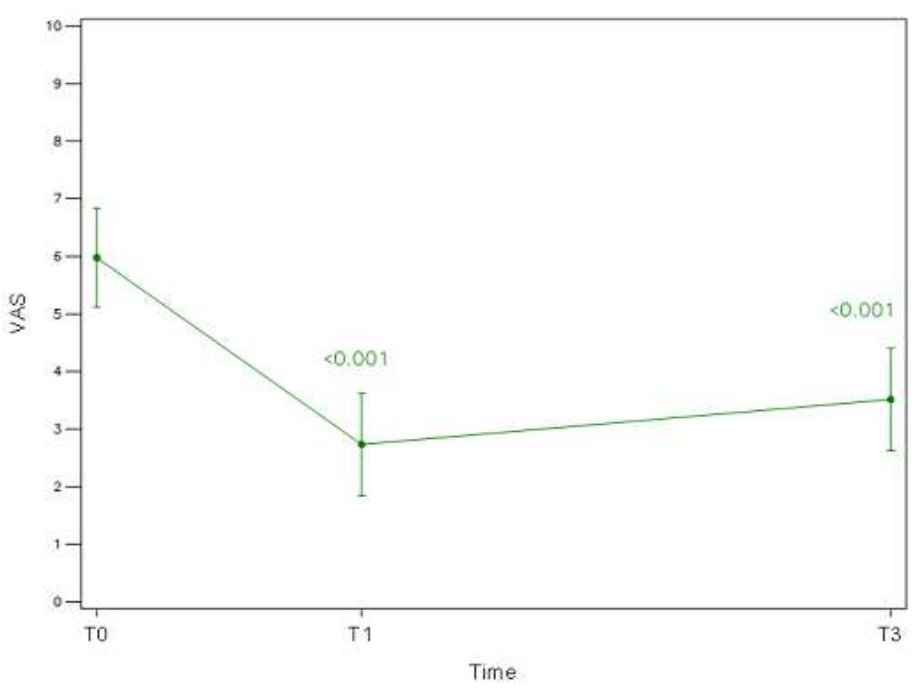


Fig. 2. Evolution (mean and $95 \%$ confidence intervals) of the two QoL questionnaires (OHIP and TMJ-QoL) and VAS from injection (T0) to 1 month after injection (T1) and 3 months after injection (T3) with $p$ values of comparison with T0 
TABLES

\begin{tabular}{|l|c|c|c|c|c|}
\hline $\begin{array}{l}\text { Because of problems with your teeth, mouth, } \\
\text { or dentures... }\end{array}$ & Never & $\begin{array}{c}\text { Hardly } \\
\text { ever }\end{array}$ & Occasionally & $\begin{array}{c}\text { Fairly } \\
\text { often }\end{array}$ & Very often \\
\hline Have you had painful? & 1 & 2 & 3 & 4 & 5 \\
\hline Have you found it uncomfortable to eat \\
any food?
\end{tabular}


Table 1. Adaptation of the Oral Health Impact Profile-14 (OHIP-14) 


\begin{tabular}{|l|c|c|c|c|c|}
\hline & $\begin{array}{c}\text { No } \\
\text { difficulty }\end{array}$ & $\begin{array}{c}\text { Mild } \\
\text { difficulty }\end{array}$ & $\begin{array}{c}\text { Moderate } \\
\text { difficulty }\end{array}$ & $\begin{array}{c}\text { Severe } \\
\text { difficulty }\end{array}$ & Unable \\
\hline Having a conversation & 1 & 2 & 3 & 4 & 5 \\
\hline Eating & 1 & 2 & 3 & 4 & 5 \\
\hline Yawning & 1 & 2 & 3 & 4 & 5 \\
\hline Sleeping & 1 & 2 & 3 & 4 & 5 \\
\hline Recreational activities & 1 & 2 & 3 & 4 & 5 \\
\hline
\end{tabular}

\begin{tabular}{|l|c|c|c|c|c|}
\hline & Never & Rarely & Once a day & Regularly & Pain not \\
controlled
\end{tabular}

\begin{tabular}{|l|c|c|c|c|c|}
\hline & Never & Seldom & Quite often & Very often & Always \\
\hline How often do you feel & 1 & 2 & 3 & 4 & 5 \\
depressed because of your \\
TMJ problems?
\end{tabular}

\begin{tabular}{|l|c|c|c|c|c|}
\hline & Not at all & Slightly & Moderately & Quite a bit & Extremely \\
\hline $\begin{array}{l}\text { Do you feel your mouth } \\
\text { improved? }\end{array}$ & 1 & 2 & 3 & 4 & 5 \\
\hline
\end{tabular}




\begin{tabular}{|l|c|c|c|c|c|}
\hline $\begin{array}{l}\text { Do you feel your facial } \\
\text { appearance has been } \\
\text { affected? }\end{array}$ & 1 & 2 & 3 & 4 & 5 \\
\hline $\begin{array}{l}\text { How have your TMJ } \\
\text { problems affected your } \\
\text { social life? }\end{array}$ & 1 & 2 & 3 & 4 & 5 \\
\hline $\begin{array}{l}\text { How have your TMJ } \\
\text { problems limited your daily } \\
\text { activities? }\end{array}$ & 1 & 2 & 3 & 4 & 5 \\
\hline
\end{tabular}

\begin{tabular}{|l|c|c|c|c|c|}
\hline & Very poor & Poor & $\begin{array}{c}\text { Neither } \\
\text { poor or } \\
\text { good }\end{array}$ & Good & $\begin{array}{c}\text { Extremely } \\
\text { good }\end{array}$ \\
\hline $\begin{array}{l}\text { How would you rate your } \\
\text { quality of life? }\end{array}$ & 1 & 2 & 3 & 4 & 5 \\
\hline
\end{tabular}

Table 2. Adaptation of the temporomandibular joint replacement quality of life questionnaire (TMJ-QoL) 


\begin{tabular}{|c|c|c|c|c|c|c|c|}
\hline \multicolumn{2}{|c|}{} & OHIP T0 & OHIP T1 & OHIP T3 & TMJ-QoLT0 & TMJ-QoLT1 & TMJ-QoLT3 \\
\hline \multirow{2}{*}{ AGE } & PCC & -0.05 & 0.18 & 0.31 & -0.14 & 0.08 & 0.19 \\
& $p$ value & 0.79 & 0.35 & 0.10 & 0.47 & 0.69 & 0.34 \\
\hline \multirow{2}{*}{ BMI } & PCC & 0.32 & -0.17 & -0.04 & 0.45 & -0.03 & -0.02 \\
& $p$ value & 0.10 & 0.3878 & 0.8504 & $\mathbf{0 . 0 1 6}$ & 0.89 & 0.90 \\
\hline
\end{tabular}

Table 3. Correlation between QoL scores and age and BMI by using Pearson correlation coefficient (PCC)

\section{REFERENCES}

[1] Butts R, Dunning J, Perreault T, Mettille J, Escaloni J. Pathoanatomical characteristics of temporomandibular dysfunction: Where do we stand? J Bodyw Mov Ther. $2017 ; 21: 534-540 . t$

[2] Fernández-de-Las-Peñas C, Galán-Del-Río F, Alonso-Blanco C, Jiménez-Garcia R, Arendt-Nielsen L, Svensson P. Referred pain from muscle trigger points in the masticatory and neck-shoulder musculature in women with temporomandibular disorders. J Pain, $2010 ; 11 ; 1295-304$.

[3] Breton-Torres I, Trichot S, Yachouh J, Jammet P. Temporomandibular joint disorders: Physiotherapy and postural approaches. Rev Stomatol Chir Maxillofac. 2016;117:217-22. 
[4] Almoznino G, Zini A, Zakuto A, Sharav Y, Haviv Y, Hadad A, et al. Oral HealthRelated Quality of Life in Patients with Temporomandibular Disorders. J Oral Facial Pain Headache. 2015; 29:231-41.

[5] Aoki KR. Review of a proposed mechanism for the antinociceptive action of botulinum toxintype A. Neurotoxicology. 2005; 26:78593.

[6] Freund B, Schwartz M. The use of botulinum toxin for the treatment of temporomandibular disorder. Oral Health 1998; 88:32-7.

[7] Freund B, Schwartz M, Symington JM. The use of botulinum toxin for the treatment of temporomandibular disorders: preliminary findings. J Oral Maxillofac Surg 1999; 57: 916-20.

[8] Shofiq I. Botulinum Toxin in the Management of Masticatory Myalgia: A MetaAnalysis of Randomised Controlled Studies. Br J Oral Maxillofac Surg. 2016; 54:145146.

[9] Freund B, Schwartz M, Symington JM. Botulinum toxin: new treatment for temporomandibular disorders. Br J Oral Maxillofac Surg. 2000; 38:466-71.

[10] Anderson GC, Gonzalez YM, Ohrbach R, Truelove EL, Sommers E, Look JO, et al. Research Diagnostic Criteria for Temporomandibular Disorders: Future Directions. J Orofac Pain. 2010; 24: 79-88.

[11] Mor N, Tang C, Blitzer A. Temporomandibular Myofacial Pain Treated with Botulinum Toxin Injection. Toxins. 2015; 7:2791-800. 
[12] Munchau A, Bhatia KP. Uses of botulinum toxin injection in medicine today. $\mathrm{Br}$ Med J 2000; 15; 320:161-5.

[13] John MT, Reissmann DR, Celebic A, Baba K, Kende D, Larsson P, et al. Integration of oral health-related quality of life instruments. J Dent. 2016; 53:38-43. [14] J. Kunjur, R. Niziol, N.S. Matthews. Quality of life: patient-reported outcomes after total replacement of the temporomandibular joint. Br J Oral Maxillofac Surg. 2016; 54:762-6.

[15] Denglehem C, Maes J-M, Raoul G, Ferri J. Botulinum toxin A: Analgesic treatment for temporomandibular joint disorders. Rev Stomatol Chir Maxillofac. 2012;113:27-31

[16] Barros Vde M, Seraidarian PI, Côrtes MI, de Paula LV. The impact of orofacial pain on the quality of life of patients with temporomandibular disorder. J Orofac Pain. 2009; 23:28-37.

[17] Borodic GE, Acquadro M, Johnson EA. Botulinum toxin therapy for pain and inflammatory disorders: mechanisms and therapeutic effects. Expert Opin Investig Drugs. 2001;10:1531-44.

[18] Slade GD, Spencer AJ. Development and evaluation of the Oral Health Impact Profile. Community Dent Health. 1994;11: 3-11.

[19] Yule PL, Durham J, Playford H, Moufti MA, Steele J, Steen N, et al. OHIP-TMDs: a patient-reported outcome measure for temporomandibular disorders. Community Dent Oral Epidemiol. 2015;43:461-70.

[20] Rhim E, Han K, Yun KI. Association between temporomandibular disorders and obesity. J Craniomaxillofac Surg. 2016; 44:1003-7.

[21] Ohrbach R, Fillingim RB, Mulkey F, Gonzalez Y, Gordon S, Gremillion H, et al. Clinical findings and pain symptoms as potential risk factors for chronic TMD: 
descriptive data and empirically identified domains from the OPPERA case-control study. J Pain. 2011;12:27-45.

[22] LeResche L, Mancl L, Drangsholt MT, Huang G, Von Korff M. Predictors of onset of facial pain and temporomandibular disorders in early adolescence. Pain. 2007;129:269-278. 